\title{
Effect of Cool Dialysate on Depression in Patients with Chronic Renal Failure Treated with Hemodialysis: A Randomized Clinical Trial
} \author{
Maryam Farhadi (iD) ${ }^{1}$, Zahra Mirhosseini (iD) ${ }^{2}$, Sedigheh Rastaghi (iD ${ }^{3}$ and Mostafa Rad (iD ${ }^{4}{ }^{*}$ \\ ${ }^{1}$ Student Research Committee, School of Nursing and Midwifery, Sabzevar University of Medical Sciences, Sabzevar, Iran \\ ${ }^{2}$ Department of Internal Medicine, School of Medicine, Non-Communicable Diseases Research Center, Vasei Hospital, Sabzevar University of Medical Sciences, Sabzevar, Iran \\ ${ }^{3}$ Student Research Committee, Department of Epidemiology and Biostatistics, School of Health, Mashhad University of Medical Sciences, Mashhad, Iran \\ ${ }^{4}$ Department of Nursing, Nursing and Midwifery School, Iranian Research Center on Healthy Aging, Sabzevar University of Medical Sciences, Sabzevar, Iran \\ "Corresponding author: Department of Nursing, Nursing and Midwifery School, Iranian Research Center on Healthy Aging, Sabzevar University of Medical Sciences, Sabzevar, \\ Iran.Email: mostafarad633@yahoo.com
}

Received 2020 December 16; Accepted 2021 January 15.

\begin{abstract}
Background: Depression is one of the most common psychiatric problems in hemodialysis patients.

Objectives: This study aimed to evaluate the effect of cool dialysate on depression in patients with chronic renal failure treated with hemodialysis.

Methods: This randomized clinical trial was performed on 66 hemodialysis patients suffering from depression. Patients were selected by a convenience sampling method and divided equally into intervention and control groups randomly by permuted block allocation, each group containing 33 patients. Data were acquired with the Beck Depression inventory-I. The intervention and control groups underwent one month of treatment with cool dialysate at 35.5 and $37^{\circ} \mathrm{C}$, respectively. The severity of depression for each group was measured at the end of each treatment stage and two weeks after the intervention. Data were analyzed using $\mathrm{R}$ version 25 software with a confidence level of $95 \%$.

Results: There was no statistically significant difference between the control and intervention groups before and after the intervention (P-values more than 0.05). While the mean of depression severity for the control group decreased from $26.15 \pm 1.46$ to $22.24 \pm$ 2.00 (P-values $<0.01$ ), the mean of depression severity for the intervention group decreased from $25.56 \pm 1.28$ to $22.41 \pm 1.65$ by the intervention (P-value $>0.05$ ).

Conclusions: The application of cool dialysate as a non-pharmacological method did not significantly reduce the severity of depression in patients undergoing hemodialysis. Therefore, it is advised to perform further studies that include more research units from different geographical locations, considering a longer intervening duration.
\end{abstract}

Keywords: Chronic Renal Failure, Depression, Cool Dialysate, Hemodialysis

\section{Background}

Hemodialysis patients experience a hefty burden of physical and emotional symptoms (1). The average prevalence of depression in hemodialysis patients is approximately $20 \%$ to $30 \%$ (2). The prevalence of depression in patients on hemodialysis is three times higher than that in the general population. These patients are prone to depression for various biological, psychological, and social reasons (3). The increased levels of cytokines and changes in neurotransmitter levels will influence the formation of depression among hemodialysis patients. According to various studies, inflammatory factors such as interleukin-1, interleukin-2, and tumor necrosis factor-alpha (TNF- $\alpha$ ) are common among these patients $(4,5)$.

Due to the severity of the issue, effective depres- sion therapies are required in routine dialysis care (6). Influential factors include pharmacological and nonpharmacological therapies such as psychotherapy (interpersonal psychotherapy, cognitive and behavior therapy), electroconvulsive therapy(ECT), or a combination of them, which bring negative feedback and dissatisfaction $(3,7)$. These treatment options, especially the administration of antidepressants, have been associated with little to no evidence of efficacy and safety. As a result, patients are often excluded from major clinical trials due to safety concerns. The number of studies carried out on subjects belonging to a small population cannot be generalized to the whole community (8). Most antidepressants are protein-bound and will be metabolized in the liver; therefore, they are not eliminated by dialysis. However, the relative activity and the excretion of these metabolites in patients with 
chronic kidney disease (CKD) are often unclear (9).

Cool dialysate is an intervention that can improve the quality of life of patients, boost sleep quality, reduce fatigue, enhance the dialysis quality, alleviate itching, and improve restless legs syndrome (RLS) $(10,11)$. Cold dialysis reduces some physical problems, which are significant causes of depression in hemodialysis patients. Therefore, this intervention can reduce depression severity among the patients (10). Among multiple studies on the application of cool dialysate, the work by Ghanbarabadi et al. (12), Soleimani et al. (13), and Parker et al. (14) led to the increased quality of sleep in hemodialysis patients. According to Sekercioglu et al.'s study (15), conducted on sleep quality, depression, and quality of life in patients with chronic renal failure, it can be concluded that cool dialysate may affect depression.

Fatigue is one of the most prevalent and distressing symptoms that affect individuals' quality of life. Due to the high frequency of fatigue in patients with chronic renal failure (70\% - 97\%) and its association with depression, it can be said that daily hemodialysis reduces the symptoms of depression and fatigue, which is in line with the findings of some studies (16-22). According to studies, cool dialysate is an appropriate method to increase the tolerance of dialysis and reduce fatigue, thereby improving depression (23). Furthermore, cool dialysate will boost the patients' levels of energy and general health with no adverse effect on dialysis adequacy (19).

\section{Objectives}

Therefore, in the light of earlier mentioned criteria, this study aimed to evaluate the effect of cool dialysate on depression in patients with chronic renal failure treated with hemodialysis in Sabzevar.

\section{Methods}

This is a two-group, triple-blind, randomized clinical parallel trial performed with a before-after design (Iranian Registry of Clinical Trials code: IRCT20200215046495N1). Sampling started on April 20, 2020, and finished on July 21,2020 , at two hemodialysis centers of Vasei Hospital and Kashefi Center. The sample size was determined using $\mathrm{G}^{*}$ Power statistical software according to the information obtained from the first 10 patients in each group. The confidence level, test power, and drop-out rate were calculated as $95 \%, 80 \%$, and $20 \%$, respectively.

After screening by a depression questionnaire, 122 patients were selected from the two centers. According to the inclusion and exclusion criteria, 66 individuals were randomly allocated by the permuted-block method to a control group (33 patients treated with $37^{\circ} \mathrm{C}$ cool dialysate) or an intervention group (33 patients treated with $35.5^{\circ} \mathrm{C}$ cool dialysate). The inclusion criteria included informed consent to participate in the study, age of older than 18 years for both genders, being ultimately conscious, and having acceptable speech and listening ability to answer the questions. The exclusion criteria included patients administrated with antidepressants, underactive thyroid (hypothyroidism), and hemoglobin count of less than 8 mg/dL (Figure 1).

Data were acquired by a demographic questionnaire and the Beck Depression inventory-II (BDI-II). The validity of BDI-II was determined in the study by Taheri Tanjani et al. (cited in Hamidi (20)) with an Internal Correlation (IC) coefficient of 0.81 . The reliability of the BDI-II questionnaire were measured by Cronbach's alpha method of as $83 \%$.

The BDI-II questionnaire consisted of 21 items composed of four sentences. The participants were supposed to encircle the one that expressed their feelings and behaviors. Each item was scored from zero to three, so the participants could achieve a score ranging from 0 to 63. Depression severity was classified into four categories based on the scores: zero to 13 (no or minimal depression), 14 to 19 (mild depression), 20 to 28 (moderate depression), and 29 to 63 (severe depression).

The hemodialysis was performed with a filter, and the device had been calibrated for temperature regulation before the process. Data were collected in three shifts in the morning, afternoon, and evening from the hemodialysis centers. Initially, BDI-II was filled out during hemodialysis before the intervention when the patient was in a calm state by the research assistant for those who met the inclusion criteria.

The temperatures of hemodialysis for the standard and cool dialysate patients were $37^{\circ} \mathrm{C}$ and $35.5^{\circ} \mathrm{C}$, respectively. To manage the research blindly, the data were collected by an assistant. The authors were unaware of both the type of intervention and the allocated groups. Patients were also unaware of the group they were assigned to. This was achieved by covering the screen of the device with a $2 \times 1$ $\mathrm{cm}$ paper so that the participants did not find out which study groups they have been placed in.

The BDI-II questionnaire was filled out before the study. One month after the intervention, to measure depression in both intervention (cool dialysate) and control groups (standard dialysate), depression was evaluated in both groups two weeks later to check the persistency of the intervention. Participants were asked to answer all the information accurately and honestly. The researcher was blinded by assigning two codes of A and B to the groups. $\mathrm{He} / \mathrm{she}$ was unaware of the allocation method of patients 


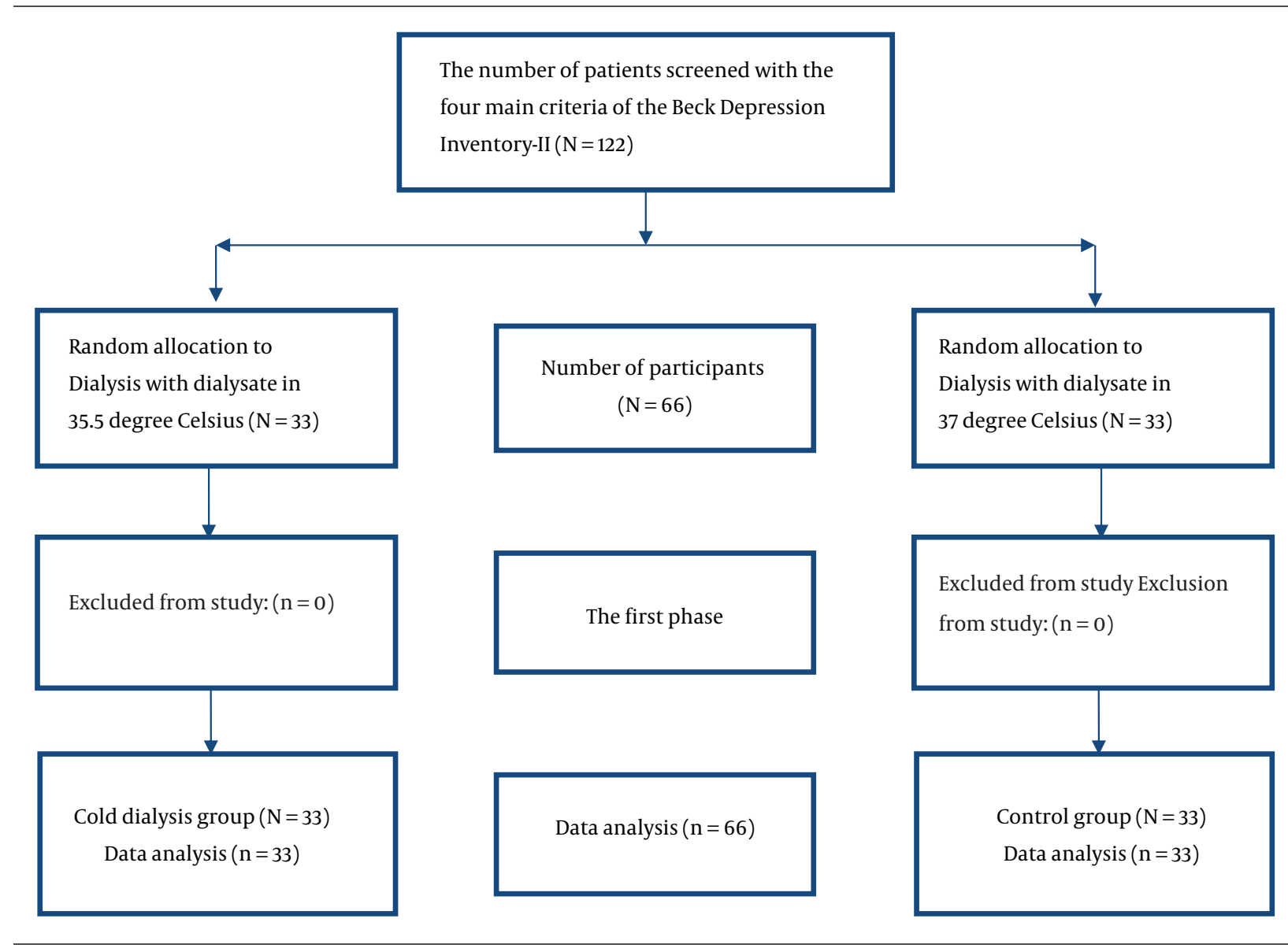

Figure 1. Flowchart of design, groups, and participants of the study

during the analysis.

After sampling and data collection, the forms were coded, and their data were imported into SPSS version 25 software to be analyzed. The Shapiro-Wilk test was used to examine the normal distribution of quantitative data. The inferential data were analyzed by the repeated-measures ANOVA (RM-ANOVA) with a significance level of 0.05 .

This study was approved and registered with the code of IR. MEDSAB. REC. 1398. 116 in the Ethics Committee of Sabzevar University of Medical Sciences. The confidentiality of patients' information was monitored throughout the study. All the subjects gave their informed consent. They were aware that participating in this study was completely voluntary and free from any obligation by the treating physician, nursing staff, the researcher, and the research assistant.

\section{Results}

Table 1 shows the demographic characteristics and medical records of patients.

There was no difference between the groups in terms of demographic and disease information using t-test, MannWhitney U-test, chi-square test, and Fisher's exact test. Before the intervention, the mean and standard deviation of depression in the control and intervention groups were $26.15 \pm 1.46$ and $25.56 \pm 1.28$, respectively. The independent $t$-test showed no significant difference between the two groups $(\mathrm{t}$-value $=0.23$, P-value $=0.81)$. One month after the intervention, the mean scores of depression in the control and intervention groups were $22.24 \pm 2.00$ and 22.41 \pm 1.65 , respectively. The independent $t$-test showed no significant difference between the two groups ( $t$-value $=-0.6$, P-value $>0.95$ ) (Table 2).

The results of RM-ANOVA for depression indicated that time had a statistically significant effect on the depression rate (P-value $<0.05$ ). There was no statistically significant effect for the interaction of time and groups (P-value $>$ 


\begin{tabular}{|c|c|c|c|c|c|}
\hline & \multicolumn{2}{|c|}{ Group } & \multicolumn{3}{|c|}{ t-test Results (Intergroup Comparison) } \\
\hline & Control, Mean \pm SD & $\begin{array}{l}\text { Intervention, Mean } \\
\quad \pm \text { SD }\end{array}$ & t & df & P-Value \\
\hline Before intervention & $26.15 \pm 1.46$ & $25.56 \pm 1.28$ & 0.23 & 64 & 0.81 \\
\hline One month after intervention & $22.24 \pm 2.00$ & $22.41 \pm 1.65$ & -0.06 & 63 & 0.95 \\
\hline Two weeks after intervention & $22.71 \pm 1.92$ & $24.28 \pm 1.96$ & -0.57 & 61 & 0.57 \\
\hline \multicolumn{6}{|l|}{$\begin{array}{l}\text { Paired } t \text {-test results } \\
\text { (intragroup comparison) (t, } \\
\text { df, and P-value) }\end{array}$} \\
\hline $\begin{array}{l}\text { Before intervention and } \\
\text { two weeks after } \\
\text { intervention }\end{array}$ & $(3.68,30,0.00)$ & $(0.78,31,0.43)$ & - & - & \\
\hline $\begin{array}{l}\text { After intervention and } \\
\text { two weeks after } \\
\text { intervention }\end{array}$ & $(-50,30,0.61)$ & $(-1.06,31,0.29)$ & - & - & \\
\hline
\end{tabular}

0.05). Furthermore, the mean of depression was not statistically significantly different between the studied groups (P-value $>0.05$ ), indicating that the severity of depression was not significantly different (Table 3 ).

\section{Discussion}

Based on the findings, it was indicated that cool dialysate did not reduce the depression level in hemodialysis patients. The study by Mahshavari et al. compared the impact of cool dialysate with standard dialysate in terms of detoxification. It revealed that cool dialysate was effective in preventing hypotension (21). Hypotension is a common complication of dialysis that causes the premature discontinuation of dialysis and severely reduces dialysis adequacy. The reduced adequacy of dialysis will give rise to severe physical complications. The present study investigated the impact of cool dialysate on reducing the physical problems of hemodialysis patients, which could alleviate the severity of depression.

Sajadi et al. (23) examined the positive effect of cool dialysate on reducing fatigue (found out to be $31.3 \%$ ) as one of the physical problems of hemodialysis patients. However, after the intervention, the level of depression did not decrease due to various physical, economic, spiritual, and psychological factors among patients. Furthermore, Kashani et al. (22) studied the alleviating impact of cool dialysate on RLS as disturbing physical factors in hemodialysis patients. Similarly, Ghanbarabadi et al. (12), Soleimani et al. (13), and Parker et al. (14) investigated the effect of cool dialysate on sleep quality. Rad and Ham et al. examined the effect of cool dialysate on itching and exhaustion and found that it improved these complications after the intervention $(24,25)$. Researchers assume that cool dialysate could reduce depression by minimizing its side effects. Besides, the application of cool dialysate improved life quality and created high energy levels and liveliness in patients, which, in turn, gave rise to reduced mortality, hospitalization, and dependence on medication.

But in this study, cold dialysis had no effect on depression. Perhaps the reason for this lack of effect is causes other than physical factors. Factors such as mental health problems, anxiety, impaired body image and self-concept, fear of death, treatment limitations, job disability, feelings of inefficiency, low life expectancy, loss of social support and family-related plans, marriage, And the high cost of living that is common in hemodialysis patients (26). Since depression is a chronic disease, it seems that the one-month intervention in this study was inadequate. It requires an extended duration to properly examine the effectiveness of cool dialysate on depression.

In this study, dialysis patients were sampled, and the intervention was performed in the COVID-19 peak. The COVID-19 disease has been the greatest public health emergency for international communities since 2020 (27). Along with physical health concerns, COVID-19 can cause mental distress (28). Symptoms of depression, anxiety, and stress caused by this epidemic have been evident globally, especially in patients dealing with chronic conditions. There were reports of suicide in some countries such as South Korea and India due to the anxiety of COVID-19 (29). Meanwhile, the media have increased the severity of fear and anxiety by frequently announcing death rates and hospitalizations (27). Psychological reactions can affect individuals' behaviors and increase their psychological problems in times of emergencies (29). Therefore, cool dialysate could be ineffective due to the high levels of anxiety and depression in hemodialysis patients due to the COVID-19 pan- 
Farhadi M et al.

\begin{tabular}{lccccc}
\hline Table 3. Changes in Severity of Depression Based on Time, Groups, and "Interaction Between Group and Time" & & & \\
\hline \multirow{2}{*}{ Source } & \multicolumn{3}{c}{ Statistical Index } & & \\
\cline { 2 - 7 } & $\begin{array}{c}\text { Sums of Squares } \\
\text { Type III }\end{array}$ & Degree of Freedom & Average Root & Frequency & P-Value \\
\hline Time & 482.53 & 2 & 241.26 & 7.04 & 0.00 \\
Group*time & 54.15 & 2 & 27.07 & 0.79 & 0.45 \\
Group & 3.62 & 1 & 3.62 & 0.01 & 0.89 \\
\hline
\end{tabular}

demic.

Due to the COVID-19 pandemic, the emergency data collection made communication difficult for both the patient and the researcher. Besides, the pandemic itself was a limiting factor of the study. Finally, a one-month intervention seemed to be inadequate for the assessment of the cool dialysate effect.

\subsection{Conclusions}

The results of the study indicated that the application of cool dialysate was ineffective in reducing the severity of depression in hemodialysis patients, but despite the ineffectiveness of this method, the severity of depression intensified by stopping the intervention. It can be inferred that a difference between the two groups could be identified by a prolonged intervention. Therefore, researchers are advised to perform the intervention over a more extended period of six to 12 months to evaluate its effectiveness.

\section{Acknowledgments}

We like to extend our gratitude to the esteemed Vice Chancellor for Research and Technology Department of Sabzevar University of Medical Sciences, the nurses, the authorities of the dialysis departments of Vasei Hospital and Kashefi Dialysis Center, and the patients who kindly cooperated with us throughout the study.

\section{Footnotes}

Authors' Contribution: Maryam Farhadi contributed to the conception, design, literature search, data acquisition, analysis and interpretation of data, and drafting of the manuscript. Zahra Mirhosseini contributed to the conception, design, and drafting of the manuscript. Sedigheh Rastaghi contributed to literature search, data acquisition, analysis, and interpretation of data. Mostafa Rad contributed to the conception, design, literature search, data acquisition, analysis, and interpretation of data, drafting of the manuscript, and critical revision of the manuscript for important intellectual content.
Clinical Trial Registration Code: The clinical trial registration code was IRCT20200215046495N1.

Conflict of Interests: The authors declare that there is no conflict of interest.

Ethical Approval: Sabzevar University of Medical Sciences approved this research (code: IR.MEDSAB.REC.1398.116).

Funding/Support: Sabzevar University of Medical Sciences supported this research.

\section{References}

1. Song YY, Hu RJ, Diao YS, Chen L, Jiang XL. Effects of Exercise Training on Restless Legs Syndrome, Depression, Sleep Quality, and Fatigue Among Hemodialysis Patients: A Systematic Review and Meta-analysis. J Pain Symptom Manage. 2018;55(4):1184-95. doi: 10.1016/j.jpainsymman.2017.12.472. [PubMed: 29247753].

2. Kargar Jahromi M, Javadpour S, Taheri L, Poorgholami F. Effect of Nurse-Led Telephone Follow ups (Tele-Nursing) on Depression, Anxiety and Stress in Hemodialysis Patients. Glob J Health Sci. 2015;8(3):16873. doi:10.5539/gjhs.v8n3p168. [PubMed: 26493429]. [PubMed Central: PMC4804080].

3. Hashemi Fesharaki M, Shahgholian N, Kashani F. Effect of stress inoculation training on the levels of stress, anxiety, and depression in hemodialysis patients. Nurs Midwifery J. 2016;14(1):88-99.

4. Taraz M, Taraz S, Dashti-Khavidaki S. Association between depression and inflammatory/anti-inflammatory cytokines in chronic kidney disease and end-stage renal disease patients: a review of literature. Hemodial Int. 2015;19(1):11-22. doi: 10.1111/hdi.12200. [PubMed: 25040322].

5. Gill J, Luckenbaugh D, Charney D, Vythilingam M. Sustained elevation of serum interleukin-6 and relative insensitivity to hydrocortisone differentiates posttraumatic stress disorder with and without depression. Biol Psychiatry. 2010;68(11):999-1006. doi: 10.1016/j.biopsych.2010.07.033. [PubMed: 20951370].

6. Chilcot J, Wellsted D, Da Silva-Gane M, Farrington K. Depression on dialysis. Nephron Clin Pract. 2008;108(4):c256-64. doi: 10.1159/000124749. [PubMed: 18401193].

7. Raymond CB, Wazny LD, Honcharik PL. Pharmacotherapeutic options for the treatment of depression in patients with chronic kidney disease. Nephrol Nurs J. 2008;35(3):257-63. quiz 264. [PubMed: 18649586].

8. Nagler EV, Webster AC, Vanholder R, Zoccali C. Antidepressants for depression in stage 3-5 chronic kidney disease: a systematic review of pharmacokinetics, efficacy and safety with recommendations by European Renal Best Practice (ERBP). Nephrol Dial Transplant. 2012;27(10):3736-45. doi: 10.1093/ndt/gfs295. [PubMed: 22859791].

9. Constantino JL, Fonseca VA. Pharmacokinetics of antidepressants in patients undergoing hemodialysis: a narrative literature review. 
Braz J Psychiatry. 2019;41(5):441-6. doi: 10.1590/1516-4446-2018-0264. [PubMed: 30843961]. [PubMed Central: PMC6796820].

10. Vasilopoulou C, Bourtsi E, Giaple S, Koutelekos I, Theofilou P, Polikandrioti M. The Impact of Anxiety and Depression on the Quality of Life of Hemodialysis Patients. Glob J Health Sci. 2015;8(1):4555. doi: 10.5539/gjhs.v8n1p45. [PubMed: 26234986]. [PubMed Central: PMC4803985].

11. Earley CJ, Silber MH. Restless legs syndrome: understanding its consequences and the need for better treatment. Sleep Med. 2010;11(9):80715. doi: 10.1016/j.sleep.2010.07.007. [PubMed: 20817595].

12. Ghanbarabadi R, Mirhosseini Z, Rakhshani MH, Estaji Z, Rad M. The effects of cool dialysate on quality of sleep among patients undergoing hemodialysis: A randomized clinical trial. J Educ Health Promot. 2019;8:56. doi: 10.4103/jehp.jehp_205_18. [PubMed: 31008123]. [PubMed Central: PMC6442248].

13. Soleimani M, Asgari M, Imani A, Tammadon M. The effect of cool temperature dialysate on sleep quality in hemodialysis patients.JAdv Med Biomed Res. 2017;25(111):128-38.

14. Parker KP, Bailey JL, Rye DB, Bliwise DL, Someren EJV. Insomnia on dialysis nights: The beneficial effects of cool dialysate. J Nephrol. 2008;21(2). S71.

15. Sekercioglu N, Curtis B, Murphy S, Barrett B. Sleep quality and its correlates in patients with chronic kidney disease: a cross-sectional design. Ren Fail. 2015;37(5):757-62. doi: 10.3109/0886022X.2015.1024555. [PubMed: 25782921].

16. Joshwa B, Campbell ML. Fatigue in Patients with Chronic Kidney Disease: Evidence and Measures. Nephrol Nurs J. 2017;44(4):337-43. [PubMed: 29160968].

17. Corfield EC. Characterising the relationship between fatigue and depression. Queensland University of Technology; 2017.

18. Farragher JF, Polatajko HJ, Jassal SV. The Relationship Between Fatigue and Depression in Adults With End-Stage Renal Disease on Chronic In-Hospital Hemodialysis: A Scoping Review. J Pain Symptom Manage. 2017;53(4):783-803 e1. doi: 10.1016/j.jpainsymman.2016.10.365. [PubMed: 28042060].

19. Toth-Manikowski SM, Sozio SM. Cooling dialysate during in-center hemodialysis: Beneficial and deleterious effects. World J Nephrol. 2016;5(2):166-71. doi: 10.5527/wjn.v5.i2.166. [PubMed: 26981441].
[PubMed Central: PMC4777788].

20. Hamidi R. Validity and reliability Beck depression inventory-II among the Iranian elderly population.J Sabzevar Univ Med Sci. 2015;22:189-98.

21. Bauer UE, Briss PA, Goodman RA, Bowman BA. Prevention of chronic disease in the 21st century: elimination of the leading preventable causes of premature death and disability in the USA. Lancet. 2014;384(9937):45-52. doi: 10.1016/S0140-6736(14)60648-6. [PubMed: 24996589].

22. Kashani E, Mirhosseini Z, Rastaghi S, Rad M. The Effect of the Cool Dialysate on the Restless Leg Syndrome in Hemodialysis Patients: Randomized Triple-Blind Clinical Trial. Iran J Nurs Midwifery Res. 2019;24(3):200-5. doi: 10.4103/ijnmr.IJNMR_133_18. [PubMed: 31057636]. [PubMed Central: PMC6485020].

23. Sajadi M, Gholami Z, Hekmatpou D, Soltani P, Haghverdi F. Cold Dialysis Solution for Hemodialysis Patients With Fatigue: a Cross-over Study. Iran J Kidney Dis. 2016;10(5):319-24. [PubMed: 27721231].

24. Rad M, Jaghouri E, Sharifipour F, Rakhshani MH. The effects of cool dialysate on pruritus status during hemodialysis of patients with chronic renal failure: A controlled randomized clinical trial. Iran Red Cresc Med J. 2017;19. doi: 10.5812/ircmj.34759.

25. Ham E, Lim J, Lee S. The effect of cool dialysis on pruritus and fatigue in hemodialysis patients. Res J Pharm Technol. 2018;11(5). doi: 10.5958/0974-360x.2018.00344.x.

26. Unsal Avdal E, Ayvaz I, Ozgursoy Uran BN, Yildirim JG, Sofulu F, Pamuk G. Opinions of hemodialysis and peritoneum patients regarding depression and psychological problems which they experience: A qualitative study. J Infect Public Health. 2020;13(12):1988-92. doi: 10.1016/j.jiph.2020.02.041. [PubMed: 32359926].

27. Schmidt B, Crepaldi MA, Bolze SDA, Neiva-Silva L, Demenech LM. Impactos na Saúde Mental e Intervenções Psicológicas Diante da Pandemia do Novo Coronavírus (COVID-19). Preprint. 2020. doi: 10.1590/SciELOPreprints.58.

28. Inchausti F, MacBeth A, Hasson-Ohayon I, Dimaggio G. Psychological intervention and COVID-19: what we know so far and what we can do. J Contemp Psychother. 2020:1-8. doi: 10.31234/osf.io/8svfa.

29. Simonetti G, Iosco C, Taruschio G. Mental Health and COVID-19: An Action Plan. Preprint. 2020. doi: 10.20944/preprints202004.0197.v2. 
Table 1. Absolute and Relative Distribution of Demographic Characteristics of Research Units by Study Groups ${ }^{a}$

\begin{tabular}{|c|c|c|c|c|c|}
\hline \multirow{3}{*}{ Statistical Index } & \multicolumn{2}{|c|}{ Group } & \multicolumn{3}{|c|}{ Statistical Results } \\
\hline & \multirow{2}{*}{ Control $(\mathrm{N}=\mathbf{3 3})$} & \multirow{2}{*}{ Intervention $(\mathrm{N}=\mathbf{3 3})$} & \multirow[b]{2}{*}{ Test Result } & \multirow[b]{2}{*}{ Degrees of Freedom } & \multirow[b]{2}{*}{ P-Value } \\
\hline & & & & & \\
\hline Age, $y$ & $58.67(14.44)$ & $56.33(14.84)$ & $t$-test; $\mathrm{t}=0.64$ & 64 & 0.52 \\
\hline $\begin{array}{l}\text { Duration of chronic renal } \\
\text { failure, mo }\end{array}$ & $58.30(50.15)$ & $90.12(95.04)$ & Mann-Whitney U; Z = 0 -0.71 & & 0.47 \\
\hline $\begin{array}{l}\text { Duration of hemodialysis } \\
\text { treatment, mo }\end{array}$ & $28.00(18.67)$ & $43.61(39.30)$ & Mann-Whitney U; Z = 0 - 0.97 & & 0.32 \\
\hline $\begin{array}{l}\text { Adequacy of dialysis, KT/V } \\
\text { Before intervention }\end{array}$ & $1.15(0.18)$ & $1.30(0.27)$ & Mann-Whitney U; Z = 0 - 0.47 & & 0.01 \\
\hline Hemoglobin level, mg/dL & $12.18(1.89)$ & $12.09(2.12)$ & $t$-test $; \mathrm{t}=0.17$ & 64 & 0.17 \\
\hline Gender & & & Chi-square $=0.28$ & 1 & 0.59 \\
\hline Female & $11(33.3)$ & $9(27.3)$ & & & \\
\hline Male & $22(66.7)$ & $24(72.7)$ & & & \\
\hline Education level & & & Fisher's Exact test & & \\
\hline Illiterate & $9(27.3)$ & $9(27.3)$ & & & 0.28 \\
\hline Basic literacy & $4(12.1)$ & $2(6.1)$ & & & \\
\hline Primary & $8(24.2)$ & $8(24.2)$ & & & \\
\hline Secondary & $3(9.1)$ & $8(24.2)$ & & & \\
\hline High school & $2(6.1)$ & $4(12.1)$ & & & \\
\hline Academic & $7(21.2)$ & $2(6.1)$ & & & \\
\hline Occupational status & & & Fisher's Exact test & & \\
\hline Employed & $2(6.1)$ & $2(6.1)$ & & & 0.99 \\
\hline Self-employed & $14(42.4)$ & $12(36.4)$ & & & \\
\hline Student & $1(3)$ & $1(3)$ & & & \\
\hline Housekeeper & $8(24.2)$ & $9(27.3)$ & & & \\
\hline Unemployed & $3(9.1)$ & $3(9.1)$ & & & \\
\hline Retired & $5(15.2)$ & $6(18.1)$ & & & \\
\hline Marital status & & & Fisher's Exact test & & \\
\hline Married & $24(72.7)$ & $28(84.8)$ & & & 0.34 \\
\hline Single & $4(12.1)$ & $2(6.1)$ & & & \\
\hline Widowed & $5(15.2)$ & $2(6.1)$ & & & \\
\hline Divorced & $0(0)$ & $1(3)$ & & & \\
\hline Income status & & & Fisher's Exact test & & \\
\hline Adequate & $12(36.4)$ & $11(33.3)$ & & & 0.99 \\
\hline Inadequate & $20(60.6)$ & $20(60.6)$ & & & \\
\hline Satisfactory & $1(3)$ & $2(6.1)$ & & & \\
\hline Place of residence & & & Chi-square $=0.08$ & & \\
\hline Urban & $25(75.8)$ & $26(78.8)$ & & 1 & 0.76 \\
\hline Rural & $8(24.2)$ & $7(21.2)$ & & & \\
\hline Living condition & & & Fisher's Exact test & & \\
\hline With spouse & $7(21.2)$ & $7(21.2)$ & & & 0.92 \\
\hline
\end{tabular}




\begin{tabular}{|c|c|c|c|c|c|}
\hline With children & $1(3)$ & $1(3)$ & & & \\
\hline $\begin{array}{l}\text { With spouse and } \\
\text { children }\end{array}$ & $17(51.6)$ & $20(60.6)$ & & & \\
\hline Alone & $4(12.1)$ & $2(6.1)$ & & & \\
\hline Other & $4(12.1)$ & $3(9.1)$ & & & \\
\hline $\begin{array}{l}\text { History of kidney } \\
\text { transplantation }\end{array}$ & & & Fisher's Exact test & & \\
\hline Positive & $1(3)$ & $4(12.1)$ & & & 0.35 \\
\hline Negative & $32(97)$ & $29(87.9)$ & & & \\
\hline Arteries pathway & & & Fisher's Exact test & & \\
\hline $\begin{array}{l}\text { Permanent catheters } \\
\text { (Shaldon) }\end{array}$ & $5(15.1)$ & $2(6.1)$ & & & 0.43 \\
\hline Fistula & $26(78.8)$ & $27(81.8)$ & & & \\
\hline Artificial veins & $2(6.1)$ & $4(12.1)$ & & & \\
\hline History of certain diseases & & & Fisher's Exact test & & \\
\hline Blood pressure & $9(27.3)$ & $11(33.2)$ & & & 0.30 \\
\hline Diabetes & $1(3)$ & $0(0)$ & & & \\
\hline Heart disease & $3(9.1)$ & $2(6.1)$ & & & \\
\hline $\begin{array}{l}\text { Blood pressure and } \\
\text { diabetes }\end{array}$ & $14(42.4)$ & $9(27.3)$ & & & \\
\hline $\begin{array}{l}\text { Blood pressure and } \\
\text { heart disease }\end{array}$ & $2(6.1)$ & $2(6.1)$ & & & \\
\hline $\begin{array}{l}\text { Blood pressure, } \\
\text { diabetes, and heart } \\
\text { disease }\end{array}$ & $3(9.1)$ & $2(6.1)$ & & & \\
\hline Polycystic kidney & $1(3)$ & $1(3)$ & & & \\
\hline Other & $0(0)$ & $5(15.2)$ & & & \\
\hline No disease & $0(0)$ & $1(3)$ & & & \\
\hline Taking antipsychotics & & & Chi-square $=0.00$ & & \\
\hline Positive & $9(27.3)$ & $9(27.3)$ & & 1 & 0.99 \\
\hline Negative & $24(72.7)$ & $24(72.7)$ & & & \\
\hline Type of antipsychotics & & & Fisher's Exact test & & \\
\hline Alprazolam & $4(12.2)$ & $8(24.3)$ & & & 0.23 \\
\hline Clonazepam & $1(3)$ & $1(3)$ & & & \\
\hline $\begin{array}{l}\text { Sodium valproate } \\
\text { (Depakene) }\end{array}$ & $3(9.1)$ & $0(0)$ & & & \\
\hline Level and Depakene & $1(3)$ & $0(0)$ & & & \\
\hline None & $24(72.7)$ & $24(72.7)$ & & & \\
\hline
\end{tabular}

${ }^{\mathrm{a}}$ Values are expressed as mean \pm SD or No. (\%). 